\title{
A Longitudinal Study of Total Body Potassium in Normal Breastfed and Bottle-fed Infants
}

\author{
MARJORIE M. RUTLEDGE, JACK CLARK, CALVIN WOODRUFF, GARY KRAUSE, AND \\ MARGARET A. FLYNN(24)
}

Departments of Nutrition and Dietetics, Community Health and Medical Practice, Child Health, the Agriculture
Experiment Station, and Department of Animal Husbandry, University of Missouri, Columbia, Missouri, USA

\section{Extract}

In a previous publication we predicted that growth as measured by ${ }^{40} \mathrm{~K}$ is best described by comparison of the semilog function of total body potassium (TBK) vs. length with a slope that differs in infants from that of children aged 3-18 years. Data for 84 infants having three or more measurements during the first year of life attest to this hypothesis, with a regression line for $\mathrm{TBK}$ and length: $\log _{\mathrm{e}} \mathrm{K}, \mathrm{g}=$ $-0.265+0.04112$ length in centimeters.

\section{Speculation}

The increasing rate of ${ }^{40} \mathrm{~K}$ accumulation between birth and the age of 1-2 years is compatible with the hypothesis that changes of body composition from that of the neonate to that of the adult is a steady process and that it is completed by the time the infant reaches a length of about $90 \mathrm{~cm}$. This process is independent of sex and initial feeding within the conditions of this study. Further methodology refinements will be needed to determine the events occurring in low birth weight infants. The role of protein-calorie malnutrition in this process warrants study.

In a previous publication (5) we predicted that growth as measured by ${ }^{40} \mathrm{~K}$ is best described by comparison of the semilog function of total body potassium (TBK) vs. length with a slope that differs in infants from that of children aged 3-18 years.

In this longitudinal study we have attempted to document that prediction by measuring total body potassium in the first 1.5 years in 84 normal infants who grew within the 16 th and 84 th percentiles of the lowa Growth Charts. The relationship between TBK and height (or length) has been well established by several investigators $(3,5,7,13,15,16)$. The uniqueness of this study is its assessment of the effects of type of feeding during the study and its attempt to delineate sex-related differences within two feeding regimens.

\section{SUBJECTS AND METHODS}

From body composition studies of 153 normal, healthy term infants recruited with informed consent of their parents, and receiving care from the University of Missouri Medical Center and community pediatricians, 84 infants had three or more measurements of TBK, length, and weight and therefore qualified for a statistical analysis of their longitudinal data. Approximately half of the babies were breastfed. About half of the babies on each diet were female. The three or more measurements of weight, height, and TBK were usually spaced at 3 weeks, 4 months, 8 months, and 10-14 months. Infants of middle socioeconomic families were admitted to the study regardless of ethnic group. The mothers were advised to follow the same feeding schedule, used the same quantity of solid food additions (21), and recorded the type and amount actually consumed each week (no solid foods were permitted before 3 months of age.)

Infants whose mothers breastfed them for 4 months or more were grouped as "breastfed" in this study. Breast and bottle feedings were ad libitum. The bottle-fed infants consumed a variety of milk-based prepared commercial infant formulas (22).

Records of illnesses and physician visits were reported by the mothers. No data from infants with prolonged illness were included in the analysis reported here.

Length was carefully ascertained to the nearest $0.5 \mathrm{~cm}$ on an infant measuring device which has a specifically constructed board with centimeter readings and a fixed headboard. Measurements were made by the same investigator $(M R)$. Infants were weighed to the nearest $100 \mathrm{~g}$.

In order to ascertain TBK, infants were measured for naturally occurring ${ }^{10} \mathrm{~K}$ in the University of Missouri`s $4 \pi$ infant liquid scintillation whole body counter (9). To "count" infants, two 26-inch long tanks are arranged facing each other (in such a way to allow for adjustable diameter) to count $10-12 \mathrm{~g}$ potassium contained in the infants with an accuracy of $4 \%$ at I SD with a counting time of $15 \mathrm{~min}$. The resolution of the $\gamma$-ray spectra for ${ }^{40} \mathrm{~K}$ and ${ }^{137} \mathrm{Cs}$ is the same as that of Kessler et al. (12). The spectra are different than that observed by Forbes (8), who used plastic scintillators. To get the best accuracy for ${ }^{10} \mathrm{~K}$ with the shortest counting time the use of a $080-1,000$ window is advisable. When both tanks are blocked, the diameter between the detecting surfaces is $17.8 \mathrm{~cm}$ ( 7 inches). The tanks may be moved apart, allowing for larger diameters which would accommodate larger animals. The effect of tank distance on $\mathrm{K}$ efficiency percentage for a $080-1,000$ window when the tanks are separated with a well diameter of $7,8,9,10$, or 11 inches is $51,49,45,43$ or $41 \%$, respectively. Efficiency calculations are based on $198 \gamma \mathrm{dpm} / \mathrm{lg}$ $\mathrm{K}$. The $\mathrm{K}$ efficiency percentage as related to source of composition and configuration for a $080-1,000$ window is $51 \%$ for $\mathrm{KCl}$ point source, $45.6 \%$ for $\mathrm{KCl}$ in a 6-pound, 7-inch diameter, 16-inch long polyethylene container and $48.5 \%$ for sugar and $\mathrm{KCl}$-filled, 4 pound, 15-inch long, 4-inch diameter plastic doll.

Each baby was centered in the infant counter and was "counted" consecutively for three 5-min measurements. Background "counts" of 5 min each werc taken before and after each infant was studied.

Standardization of the infant counter was done with specifically constructed heavy cotton phantoms filled with known amounts of sugar and $\mathrm{KCl}$. Three phantoms whose average anthropometric measurements were those of a 1-month, 4-month, and 12-monthold baby were used (17). The coefficient of repeatability of counts of 10 infants counted over a period of several days was 0.99 .

Further standardization of the infant counter was also verified by "counting" very young pigs of different sizes and ages and chemically analyzing their whole bodies (18). Thirteen pigs weighing $1.2 \mathrm{~kg}$, eight pigs weighing $5.4 \mathrm{~kg}$, and nine pigs weighing $13.5 \mathrm{~kg}$ were counted and then slaughtered when each reached its predetermined weight. Average TBK assessed by chemical analysis was $13.6 \mathrm{~g}$. The average $\mathrm{TBK}$ by ${ }^{40} \mathrm{~K}$ technique was $12.8 \mathrm{~g}$ with $\mathrm{r}=$ 0.96 .

Statistical methods used are described by Snedecor and Cochran 
Table 1. Age, sex, and diet compared with average total body potassium (TBK), length, and weight of infants studied longitudinally

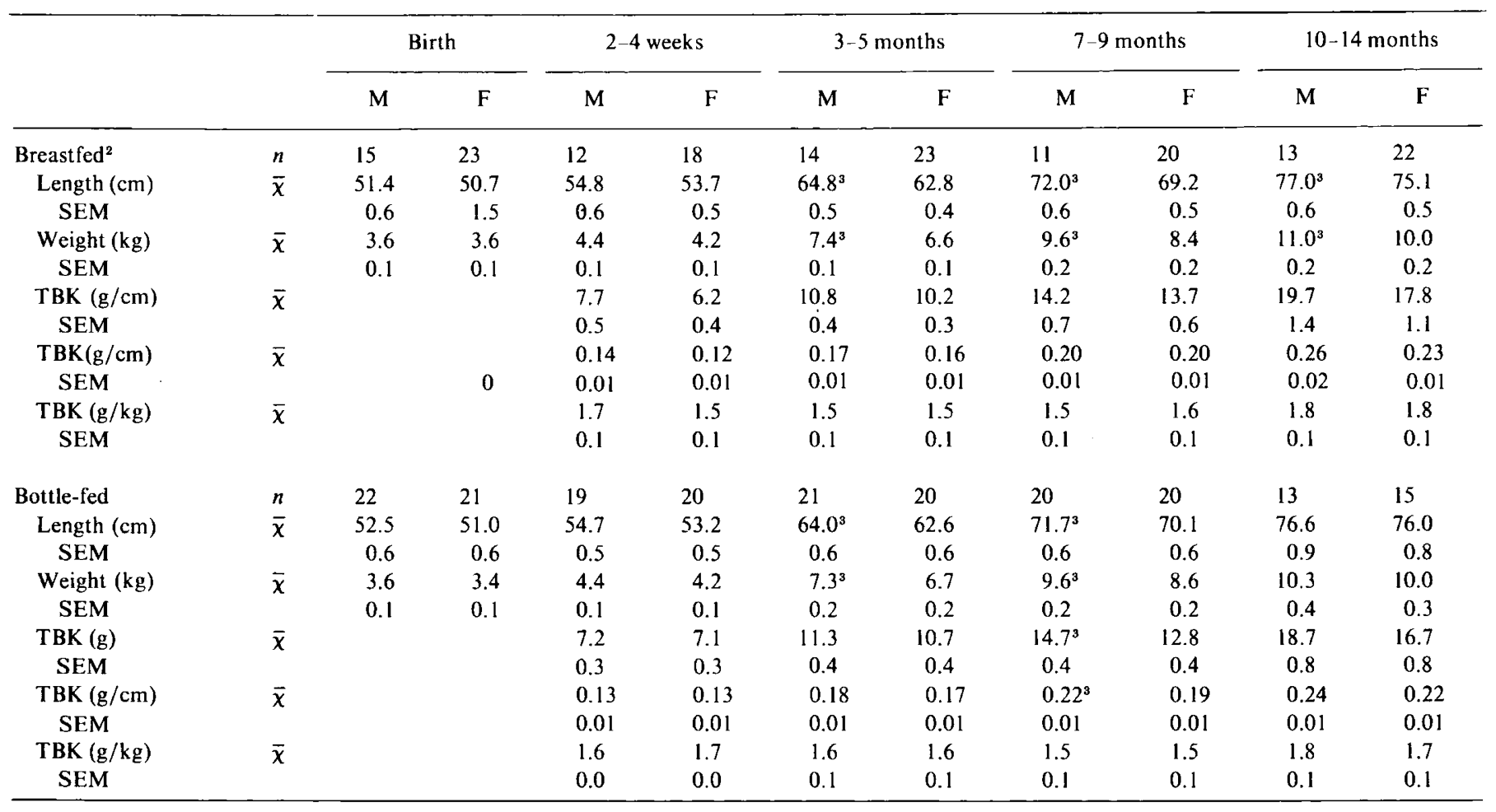

${ }^{1}$ The mean age for each group is the midpoint of the range. M: male; F: female.

${ }^{2}$ These infants were breast-fed for the first 4 months or more.

${ }^{3} p \leq 0.05$ within each diet.

(19). Means of various measurements were compared, using the two-group $t$-test. The pooled data growth curve was estimated using the linear regression technique for logarithmic-dependent variable, and parallelism studies among growth curves were done using methods associated with the analysis of covariance. Our use of semilog function is consistent with other investigators who assume that growth (accumulation of ${ }^{40} \mathrm{~K}$ here) is an exponential process $(14,20)$.

\section{RESULTS}

Means and standard errors estimated from the indicated number of children measured in selected age classes are given in Table 1. We admitted data when the child had at least three longitudinal measurements; therefore, a particular child's data may not be present in all the age classes chosen for the statistical analyses.

Table I shows that the sample of infants selected for longitudinal study was similar whether breastfed or bottle-fed or boy or girl in reference to average birth weight or/and length. These babies showed no statistical significant difference at 2-4 weeks in TBK, length, or weight. There were sex-related statistically significant differences $(P \geq 0.05)$ present in average length and weight of breastfed boys vs. girls at ages 3-5 months, at 7-9 months, and at 10-14 months. The boys were not "older" in any of these age ranges. The girls were shorter and weighed less. Potassium was not significantly different between boys and girls.

A few sex-related statistically significant differences were noted in bottle-fed babies in average length and weight at ages 3-5 months and at 7-9 months of age; girls weighed less and were shorter in length; boys had more K than girls at age 7-9 months ( $P$ $\leq 0.05$ ) and more $\mathrm{K}$ per $\mathrm{cm}$ length only at 7-9 months.

Since the only significant differences found for TBK per $\mathrm{cm}$ of length was at age 7-9 months, all data were plotted together in Figure 1, which shows TBK values graphed on a semilog scale vs. length for all infants studied.

Statistical analysis of the longitudinal data was done by

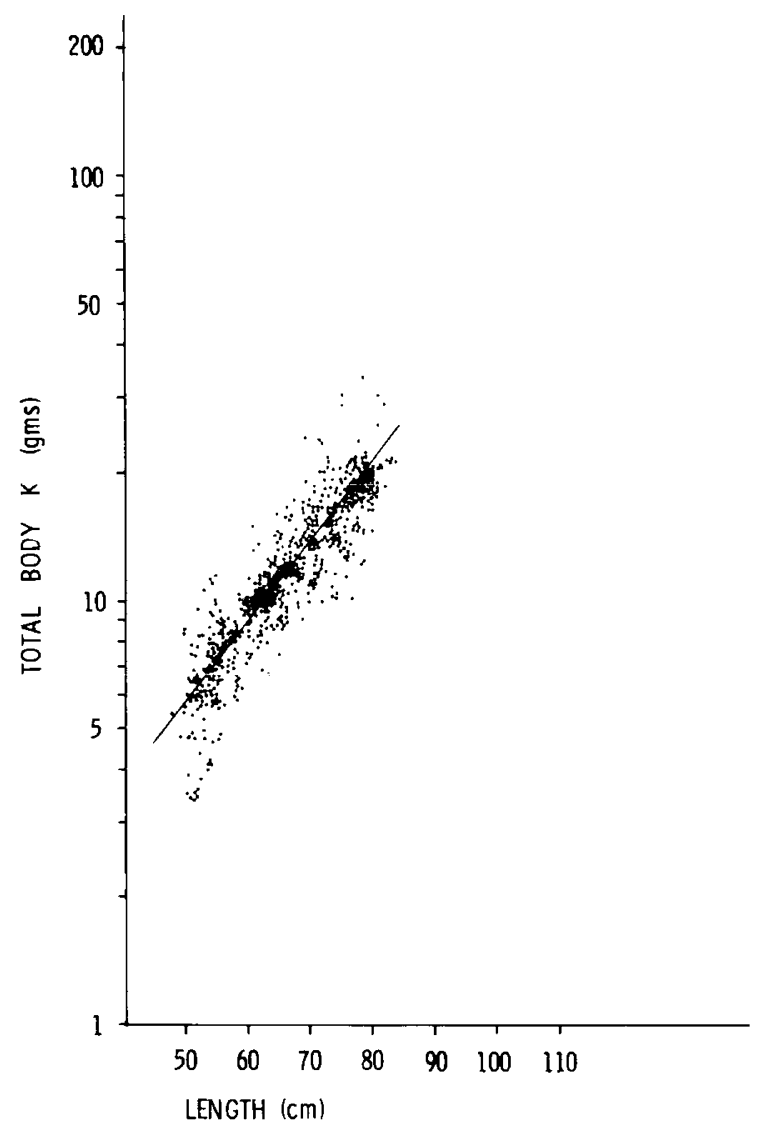

Fig. 1. Scatter diagram and mean regression line for log $\mathrm{K}$ vs. height for 153 normal breastfed and bottle-fed infants ( 84 measured three or more times during the first year of life.) 
comparing the slopes of growth among the 84 infants with at least three measurements in time. The slopes were found to be parallel, demonstrating similar rates of growth for all infants in the study, without regard to sex or type of diet in these normal babies. The data are best described by a single regression line for TBK and length $(r=0.89 ; \mathrm{SD}=0.19)$ : $\log _{\mathrm{e}} \mathrm{K}, \mathrm{g}=-0.265+0.04112$ length in centimeters.

Figure 2 shows the data cited above compared with the regression lines for the mean and tolerance region of $68 \%$ of the population studied by Flynn et al. (5) in children ages 3-18 years. The main regression lines from reference 5 were: females: $\log _{e} \mathrm{~K}$, $\mathrm{g}=1.595+0.01942$ height in centimeters for height $\leq 135 \mathrm{~cm}$; $\log _{\mathrm{e}} \mathrm{K}, \mathrm{g}=2.574+0.01215$ height in centimeters for height $>$ $135 \mathrm{~cm}$; males: $\log _{\mathrm{e}} \mathrm{K}, \mathrm{g}=1.761+0.0182$ height in centimeters.

Our slope, 0.04112 , is significantly $(P \leq 0.01)$ higher than those reported in the previous study (5). These data are evidence confirming their prediction that infants in the first year have a different pattern of growth in reference to TBK and length than do older children. The variability of the infant data as compared with the data of the older children is observable in Figure 2. Note the wide range of TBK at $50-60 \mathrm{~cm}$ of length.

\section{DISCUSSION}

Although the statistical analysis of our data shows a significant difference in grams of TBK and in TBK per cm between bottle-fed boys and girls at 7-9 months, this was not apparent as they aged to 10 - 14 months. We measured a fewer number of those children at age 10-14 months, however, we believe that, although the mathematics may show significance, the biologic aspects are probably not significant. Burmeister and Romahn (2), have reported ${ }^{40} \mathrm{~K}$ data for newborn and premature babies in their search for methodology to assess cell mass. From their data on 101 newborn infants they concluded that the relationship of $K$ and weight show correlation coefficients of 0.69 and 0.08 whereas $K$ and length show coefficients of 0.46 and 0.63 for girls and boys, respectively. (None of our children were counted at birth because of the myriad of adjustments newborns must make in their early extrauterine environment.) With the knowledge of how difficult accurate measurements of length in newborn can be, one wonders whether all their babies were measured by the same investigator. With the use of tapemeasure as a tool, accuracy may have been jeopardized if the measurements were done by many individuals.

In comparing our infant data with those of Novak (15) in average length, weight, and TBK at age 1, 4, 8, and 12 months, we find agreement in the size of infants studied. He reported that infant boys had statistically significantly higher amounts of TBK than girls at age $1,4,9$, and 12 months, which is in disagreement with our data. Novak has not published grams TBK per $\mathrm{cm}$ length for his infants. However, mathematical analysis of his published "average TBK" and "average height" yields values that are very much like ours at about $1,4,8$, and 12 months. Our data, graphically plotted in Figures 1 and 2 as a semilog function of TBK, can not be compared visually with the plotted data of Novak who described total body $\mathrm{K}$ vs. height in the first year of life as two intersecting lines (15) because he plotted absolute values of TBK. When we use the same method of plotting absolute values of TBK and length for our data, there is no break in the accretion of TBK in the first year of life for boys or girls.

Mann et al. (13) found in their studies with children aged 1.5-27 months that for every function of weight $(\mathrm{W})$ and height $(\mathrm{H})$, the tolerance limits were narrower for the prediction of the log TBK than for prediction of TBK and that the $\log$ TBK in milliequivalents was most accurately predicted by $\mathrm{W} / \mathrm{H}^{2}$.

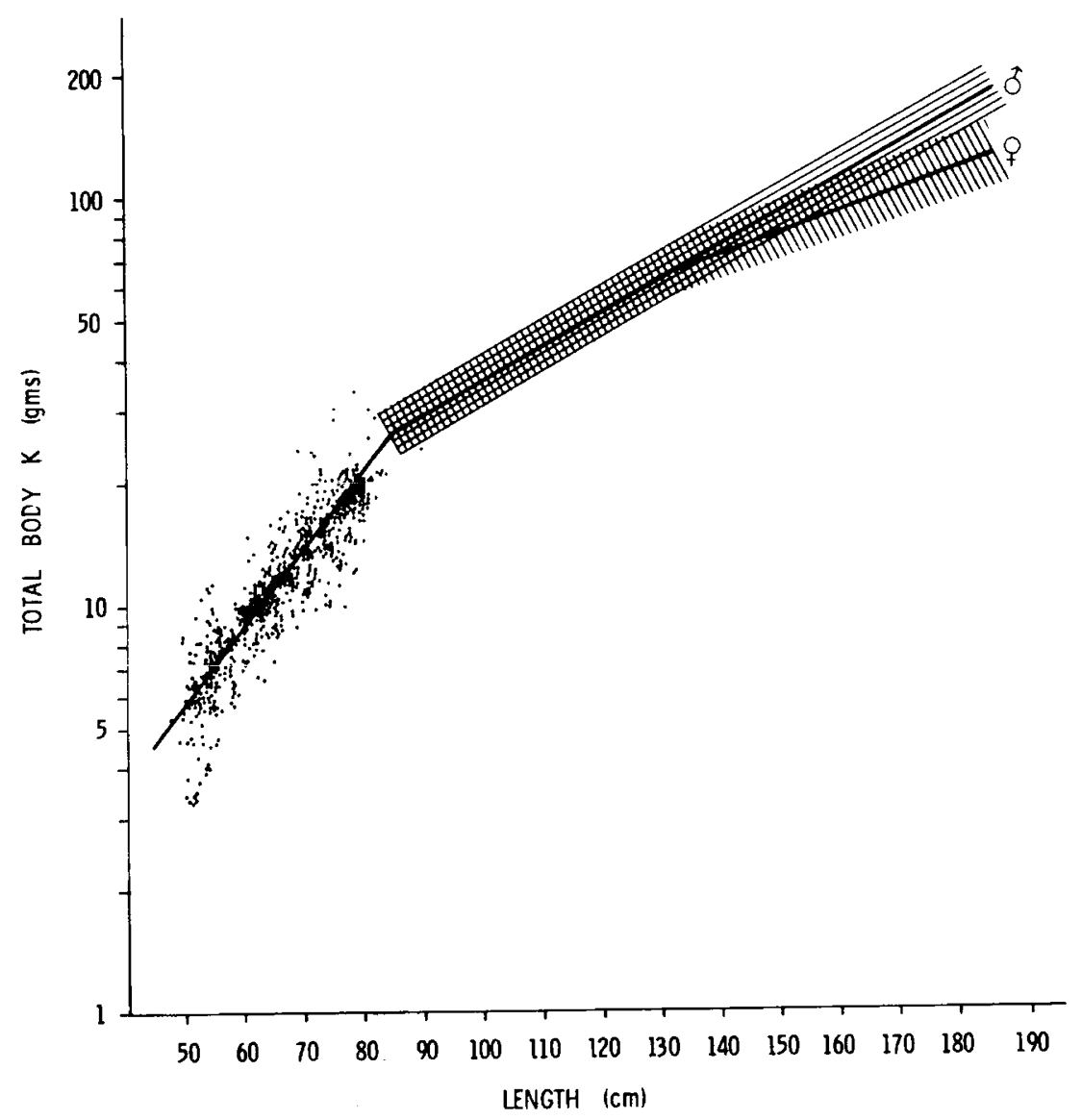

Fig. 2. Scatter diagram and mean regression line for $\log \mathrm{K}$ vs. height for 153 normal infants ( 84 measured three or more times) compared with the regression lines for the mean and tolerance region of $68 \%$ of 232 boys and 230 girls aged 3-18 years measured once by Flynn $e t$ al. (5). 
If one accepts the fact that measurement of TBK is a gauge of lean body mass because potassium is an intracellular electrolyte which is found in very small amounts in adipose tissue, then one may deduce that the babies in our study had similar increments of lean body mass in reference to length regardless of sex or type of milk fed.

If one further examines our data to ascertain whether, even though TBK is the same in our infants, weight might be in favor of greater amount of fat in relation to type of feeding, no difference is observable (Table 1). From our study we cannot confirm the observations of several investigators that bottle-fed infants are "heavier" than breast-fed infants in the first year of life $(1,4,6)$. The documentation of relative body compartments of leanness and fatness in reference to type of feeding is necessary to show that increased weight equals increased fat. Most of their observations are based on weight alone. Bernal and Richards (1) reported that breastfed babies had different arousal levels, cried more, and spent less time in bed and that these activities may have promoted leanness. Several investigators have suggested that bottle-fed babies can be subtly force-fed, thus introducing greater number of calories $(4,6)$. Jackson et al. (11), reporting a study of 599 infants of whom 215 were breastfed for 4-6 months, found no difference in weight gain between breastfed and bottle-fed infants during the first 4 months of life. Hall (10), in a recent publication, states that breastfed babies control their feeding in response to changes in the biochemical constitution of the milk, which affects appetite during each feeding. We had no control over amounts of milk fed the babies since they were fed ad libitum. However, additions of solid foods were made at the same time and in the same amounts in both groups of infants. We did no "activity" studies in our infants.

\section{SUMMARY}

Increase in total body potassium in infants during the first year of life is best described by a single regression line of the logarithm of total body potassium vs. length with a slope that differs from that of children aged 3-18 years.

\section{REFERENCES AND NOTES}

1. Bernal, J., and and Richards, M. P. M.: The effects of bottle and breast feeding on infant development. J. Psychosom. Res., 14: 247 (1970).

2. Burmeister, W., and Romahn, A.: Potassium content in full-term and premature babies: Energetics for the synthesis of body cell mass. In: F. Linneweh: Current Aspects of Perinotology and Physiology of Children, p. 139 (Springer, Berlin 1973).

3. Cheek, D. B. (Editor): Human Growth: Body Composition, Cell Growth, Energy and Intelligence (Lea \& Febiger, Philadelphia, 1968).

4. Dwyer, J., and Mayer, J.: Overfeeding any obesity in infants and children. Nutr. Diet., 18: 123 (1973).

5. Flynn, M. Woodruff, C. Clark, J., and Chase, G.: Total body potassium in normal children. Pediat. Res., 6: 239 (1972).

6. Fomon, S. J., Thomas, L. N., Filer, L. J., Ziegler, E. E., and Leonard, M. T. Food consumption and growth of normal infants fed milk-based formulas Acta Paediat. Scand., Suppl. 223 (1971).

7. Forbes, G. B.: Stature and lean body mass. Amer. J. Clin. Nutr. 27: 595 (1974).

8. Forbes, G. B.: A $4 \pi$ plastic scintillation detector. Int. J. Appl. Radiat. Isotopes, 19: $535(1968)$.

9. Graham, E. R.: Small animal and infant liquids scintillation counter. Int. J. Appl. Radiat. Isotopes, 20: 249 (1969).

10. Hall, B.: Changing composition of human milk and early development of an appetite control. Lancet, April 5, 1975.

11. Jackson, R. L., Westerfiel, R., Flynn, M. A., Kimball, E. R., and Lewis, R.: Growth of well-born american infants fed human and cow's milk. Pediatrics, 33: 642 (1964).

12. Kessler, W. V., Ziemer, P. L., Christian, J. E., and Shaw, S. M.: A $4 \pi$ liquid scintillation whole body counter-I. Design, operating characteristics, and calibration. Int. J. Appl. Radiat. Isotopes, 19: 287 (1968).

13. Mann, M. D., Bowie, M. D., and Hansen, J. D. L.: Total body potassium estimations in young children: The interpretation of results. Pediat. Res., 8: 879 (1974).

14. Nelder, J. A.: A note on some growth patterns in a simple theoretical organism. Biometrics, 17 (2): 220 (1961).

15. Novak, L. P.: Total body potassium during the first year of life determined by whole body counting of ${ }^{\circ 0} \mathrm{~K}$. J. Nucl. Med., 14: 550 (1972).

16. Pierson, R. N., Lin, D. H. Y., and Phillips, R. A.: Total body potassium in health: Effects of age, sex, height, and fat. Amer. J. Physiol., 226: 206 (1974).

17. Rutledge, M.: Method for measuring body potassium in infants and its application to infants fed human milk and simulated formula. Master's thesis, 1973. University of Missouri, Columbia.

18. Schmidt, $\mathrm{M} .{ }^{\circ}{ }^{\circ} \mathrm{K}$ as a predictor of body composition in swine. M. S. Thesis, 1971 University of Missouri, Columbia.

19. Snedecor, G. W., and Cochran, W. G.: Statistical Methods, Ed. 6 (Iowa State University Press, Ames, Iowa, 1967).

20. Stevens, W. L.: Asymptotic regression. Biometrics, 7: 247 (1951).

21. Beech-Nut, Baker/Beech-Nut Corp., Canajoharie, N.Y.

22. Enfamil, Similac, SMA.

23. This study was partially supported by the Agriculture Experiment Station, the General Clinical Research Center, and the Medical Research Fund-Medical Center, University of Missouri, Columbia, Mo., by Mead Johnson Laboratories, and by the Baker/Beech-Nut Corp.

24. Requests for reprints should be addressed to: M. A. Flynn, Ph.D., M757 Medical Center, Columbia, Mo. 65201 (USA).

25. Accepted for publication September 30, 1975. 